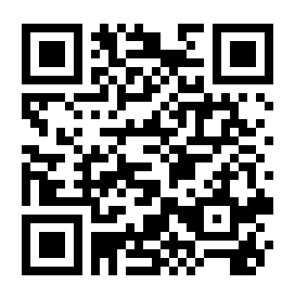

\title{
Queering Carreiras
}

Interseccionalidades De Gênero, Sexualidade e Classe na Trajetória de um Bailarino

Sidinei RochA-DE-OliveIRA, Universidade Federal do Rio Grande do Sul Aline Mendonça Fraga, Universidade Federal do Rio Grande do Sul

Gênero, sexualidade e classe marcam as trajetórias profissionais e se intercruzam na compreensão dos contextos de carreira. Para explorar estas interrelações, este artigo tem por objetivo analisar uma trajetória queer, a partir da vivência de um artista, gay, de classe baixa, nascido no sul do Brasil. Com tal propósito, os conceitos de carreira são (re)discutidos com base na teoria queer. A discussão de gênero, sexualidade e classe é aprofundada pela análise de intersecção destes elementos na formação da trajetória profissional. O percurso metodológico constitui-se com enfoque biográfico, buscando combinar observação, interação e reflexão durante e após a recolha da história de vida a ser contada. Andrew, o entrevistado, é bailarino, ator, e faz performances em festas. Adota uma postura queer em seu cotidiano, refletidas no modo de vestir e agir próprio, em diferentes espaços de atuação. Como principais contribuições do artigo destacam-se: 1) a ênfase para a interseccionalidade no campo de carreiras, apontando as múltiplas diferenças que somam e marcam trajetórias; 2) a apresentação das potencialidades da teoria queer para aprofundar e dar novas direções e dimensões para os estudos de carreira; 3) o uso de metodologias qualitativas para os estudos de carreira.

PALAVRAS-ChAVE: Carreira. Queer. Gênero. Sexualidade. Classe Social. 


\section{Introdução}

O tema de carreira tem crescido em interesse e número de estudos (BARUCH; GUNZ, 2015), todavia, as pesquisas seguem priorizando carreiras tradicionais, sobretudo aquelas ligadas às organizações (GUEST; STURGES, 2007). Ainda são poucos os trabalhos que se voltam para a compreensão de trajetórias de atores socialmente marginalizados (BARUCH; VARDI, 2016; FRAGA et al., 2019; PRASAD; D'ABATE; PRASAD, 2007) e ocupações pouco tradicionais (DELUCA; ROCHA-DE-OLIVEIRA, 2016). Além disso, estudos sobre carreiras têm priorizado um perfil de indivíduo: homem, branco, heterossexual. São raros os trabalhos que analisam gênero e sexualidade (CHARLES; ARNT, 2013; DATTI, 2009; FRAGA et al., 2019) ou classe social (GUEST; STURGES, 2007; STEFFY, 2017) e ainda mais incomuns aqueles que buscam compreender como esses elementos marcam as trajetórias profissionais de modo integrado (FRAGA; GEMELLI; ROCHA-DE-OLIVEIRA, 2019).

$\mathrm{Na}$ medida em que carreiras sempre ocorrem em contextos (GUNZ; MAYRHOFER, 2019; MAYRHOFER; MEYER; STEYER, 2007) interessa compreender os elementos que marcam o campo em que se insere uma carreira, bem como os elementos que marcam trajetórias, evitando perceber as ações dos indivíduos em um vazio laboral (SULLIVAN; BARUCH, 2009). Gênero, sexualidade e classe marcam as trajetórias profissionais e se intercruzam na compreensão dos contextos de carreira. Desta forma, este trabalho tem por objetivo analisar uma trajetória queer, a partir da vivência de um bailarino, gay, de classe baixa, nascido no sul do Brasil.

Adotou-se uma perspectiva metodológica compreensiva e histórica para analisar a trajetória de Andrew, o entrevistado. Como base da análise, tomou-se a ideia de carreira como uma trajetória social e historicamente inscrita, integrando dimensão pessoal e profissional (DELUCA; ROCHA DE OLIVEIRA; CHIESA, 2016). Os conceitos de carreira são discutidos a partir da teoria queer (MISKOLCI, 2009), que vem se destacando como base para análise crítica nos estudos organizacionais (SOUZA, 2017) e para pesquisas sobre segregação ocupacional (McDONALD, 2016). Além disso, a discussão de gênero, sexualidade e classe são trabalhadas pela intersecção destes elementos na formação da trajetória profissional. 
O estudo apresentado está estruturado em quatro partes. A primeira traz a discussão teórica com a aproximação da teoria queer e dos estudos de carreira e a discussão de classe e gênero com base na interseccionalidade. $\mathrm{Na}$ segunda, é apresentada a metodologia empreendida para realização da pesquisa. A terceira parte detalha a trajetória de Andrew na dança. Na quarta parte, discutem-se as vivências do entrevistado com base na teoria. Por fim, são apresentadas as conclusões do estudo.

\section{Queering carreiras}

Os estudos sobre carreira têm destacado a importância da análise das trajetórias construídas em atividades marginalizadas e/ou não tradicionais (BARUCH; VARDI, 2016) e a necessidade de busca por maior interdisciplinaridade (KHAPOVA; ARTHUR, 2011; LAWRENCE, 2011). No entanto, as pesquisas atuais ainda permanecem focadas em carreiras tradicionais (BARUCH; VARDI, 2016; GUEST; STURGES, 2007) e predomina o olhar para a apresentação de modelos, a exemplo da carreira sem fronteiras. Outro modelo em voga é o da carreira proteana (BRISCOE; HALL; DEMUTH, 2006), cuja teoria é construída de forma dicotômica, transferindo a responsabilidade da organização para o indivíduo. Além disso, conservam o foco nas trajetórias de pessoas de classe média com profissões definidas no curso superior (PORTER; WOO; TAK, 2016).

A discussão de gênero, classe e sexualidade quase sempre é tratada separadamente, sem que se explorem possíveis interrelações. Dentre os três, gênero é o tema mais frequente, normalmente analisando carreiras de mulheres (FRAGA; GEMELLI; ROCHA-DE-OLIVEIRA, 2019; FRAGA; ROCHA-DE-OLIVEIRA, 2020). Nessa perspectiva, merece destaque a discussão sobre carreira caleidoscópica (SULLIVAN; MAINIERO, 2008) que surge para problematizar e discutir carreiras femininas, mas sem romper - possivelmente, até reforça - a análise binária de sexo. A discussão de classe, está frequentemente associada com trajetórias de mobilidade social, vivenciada por pessoas da classe trabalhadora e seu processo de ajustamento ao mercado de trabalho (THOMPSON; SUBICH, 2013). De modo semelhante, estudos que envolvem carreira e sexualidade - embora contribuam para revelar como a discriminação influencia escolhas e trajetórias profissionais (PARNELL et al, 2012) - destacam o ajustamento necessário das pessoas 
tidas como "diferentes" para atender ao padrão esperado no mercado de trabalho (KAPLAN, 2014; NG; CHWEITZER; LYONS, 2012).

Como caminho alternativo para problematizar e discutir o campo dos estudos de carreira, a teoria queer surge como abordagem interdisciplinar, voltada para a inclusão da diferença, rompendo com o foco binário tradicionalmente utilizado. A teoria queer não é uma abordagem estática, é uma atitude disruptiva permanente, que busca assumir uma postura de reflexão (e transformação) sobre ideias acerca do conhecimento, das relações de poder e da identidade. A postura queer oportuniza crítica nos debates que envolvem, sobretudo, gênero, trabalho e organização (PULLEN et al., 2016).

Originária nos Estados Unidos, no final da década de 1980, os estudos queer emergem como um conjunto interdisciplinar de pensamento, primeiramente na área de ciências humanas, que estabelece uma tensão com a teoria social tradicional (MISKOLCI, 2009). O estranhamento e a crítica queer para com a teoria dominante decorre da sua ordem correspondente à heterossexualidade, até os anos 1990. Assim, "o pressuposto heterossexista do pensamento sociológico era patente até nas investigações sobre sexualidades não-hegemônicas. A despeito de suas boas intenções, os estudos sobre minorias terminavam por manter e naturalizar a norma heterossexual" (MISKOLCI, 2009, p.151). Os pontos centrais desta contraposição estavam na crítica à análise dividida em níveis macro e micro, à construção de grandes narrativas definidoras da conduta de grupos sociais e a qualquer forma de categorização. Teorizações queer valorizam estudos empíricos e pesquisas que questionam definições pré-estabelecidas com relação à binariedade, a exemplo de sexo e raça (KING, 2016).

Questionando os pressupostos da diferença para evidenciar significados que estão ocultos pelas categorias binárias, o enfoque queer se propõe a rompimentos. Assim, adotar a abordagem queer é buscar questionamento e descontrução constante (McDONALD, 2016). Além disso, implica em questionar quase todo conhecimento estabelecido nos estudos organizacionais, tais como agente/estrutura, individual/social, micro/macro, homem/mulher, branco/não-branco.

Estudos como o de King (2016), que faz uma análise queer sobre a segregação ocupacional, destacam a necessidade de revisitar o tema buscando uma abordagem que transgrida as categorias fixas, compreendendo-as como forças que delimitam e normatizam as 
condutas, ao mesmo tempo que silenciam quem não se adequa à norma. Seguindo a proposta de King (2016), é possível fazer uma aproximação com os estudos de carreira, assumindo como princípios para esta reflexão:

(1) todo conhecimento pode ser submetido a reflexões críticas sobre suas bases teóricas e pressupostos;

(2) as identidades são elaborações normativas, que servem para disciplinar relações de poder e contribuem para a manutenção das diferenças;

(3) a nomeação das diferenças contribui para que seu significado seja compreendido;

(4) as identidades podem ser - e muitas vezes estão - ocultas.

Segundo McDonald (2016), a teoria queer faz uma crítica ao pensamento binário e ao foco na compreensão de identidades sociais, que simplificam o entendimento da organização das ocupações em termos de raça e gênero, deixando de explorar outras formas de diferenças. Apesar de existirem múltiplas possibilidades de compreensões identitárias, os estudos tendem a focar em apenas um eixo de diferença. Além disso, esta abordagem aponta para a ausência de intersecionalidade nas análises produzidas. A interseccionalidade parte da ideia de que as identidades sociais são sempre experimentadas simultaneamente, portanto o privilégio e a desigualdade não são redutíveis a apenas um eixo de diferença.

Aproximando a discussão do campo de carreira, recorre-se aos estudos da Escola de Chicago, nas obras de Becker (1951; 2008) e Hughes (1937; 1958). Esses autores exploraram trajetórias não tradicionais e chamaram de carreiras desviantes aquelas relacionadas com alguma subcultura, tais como os usuários de maconha (BECKER, 2008), strippers (RONAI; CROSS, 2003) e músicos (FAULKNER, 2003). Nesses estudos, explora-se a percepção de estágios típicos pelos quais as pessoas passam, formados por turning points - ou pontos de virada - (DELUCA; ROCHA DE OLIVEIRA, 2016) que fazem com que o indivíduo desviante siga ou não por determinado caminho.

A perspectiva de carreira adotada por Hughes $(1937 ; 1958)$ segue a corrente interacionista, possibilitando colocar em evidência a interdisciplinaridade necessária para a compreensão de trajetórias individuais ou de grupos estudados. A abordagem interacionista leva ao 
fortalecimento da base relacional e contextual dos conceitos, permitindo romper com as dicotomias pré-determinadas. Para Hughes, uma carreira pode ser compreendida como "a sequência de papeis, status e cargos realizados pelo indivíduo" (HUGHES, 1937, p. 404). Sua definição abrange, portanto, tanto atividades ligadas ao trabalho como os papeis sociais vivenciados ao longo da trajetória, considerando a interação dos indivíduos com a sociedade e os significados produzidos individualmente a partir dessa interação.

Adicionando a dimensão temporal, DeLuca, Rocha-de-Oliveira e Chiesa (2016, p. 15) definem carreira como "uma trajetória retrospectiva e projetada, dinâmica e mutável, de um indivíduo ou coletividade, revelando negociações entre objetividades e subjetividades". Esta definição busca articular os conceitos de Hughes $(1937 ; 1958)$ e de Velho (2003), explorando as noções de projeto, metamorfose e negociação da realidade. Segundo Velho (2003), projetos são condutas, individuais ou coletivas, voltadas para propósitos objetivos que podem influenciar uns aos outros. O campo de possibilidades é o conjunto de caminhos, dentro de um determinado contexto histórico e socialmente inscrito, disponível para os indivíduos e que será adequado em função dos projetos individuais e coletivos existentes. Metamorfose é a possibilidade de circular entre diferentes esferas da vida social e de assumir projetos distintos em função dessas. Nesse todo de interações, ocorre a negociação da realidade, em um jogo de permanência e mudança (VELHO, 2003).

Esse conceito, focado na relação dinâmica e temporalmente inscrita entre indivíduo, coletividade e contexto, permite uma aproximação queer para a compreensão das vivências ocupacionais, uma vez que prentede romper com as limitações binárias. Assume a trajetória como processo, no qual as mudanças podem ocorrer ao longo do tempo e contempla a articulação de diferentes grupos por meio da noção de projeto.

\section{Classe, sexualidade e gênero em intersecção}

Referências de classe social, de gênero e de orientação sexual influenciam nos projetos e possibilidades que se apresentam para a construção de carreiras, já que estes papeis disponíveis deliberam oportunidades e condicionam acesso e mobilidade dentro da estrutura social. A classe "atribuída aos indivíduos no nascimento, com base no 
status de classe de sua família de origem" (JONES, 2003, p. 803-804) bem como gênero e sexualidade, são elementos da diferença que podem cercear a disponibilidade de mobilidade (FRAGA; ROCHA-DEOLIVEIRA, 2020). Por outro lado, a ruptura com padrões sociais tende a ampliar o espaço de escolhas e perspectivas profissionais.

A classe social de origem está relacionada com a trajetória vivida, com o passado e a memória. Nesse sentido, contribui para perspectivas de futuro, ao representar uma dimensão temporal que pode ultrapassar o período de carreira individual (GAZTAMBIDE-FERNÁNDEZ; VANDERDUSSEN; CAIRNS, 2014). Também, de modo mais ou menos sutil, o reforço de estereótipos sociais e sexuais de gênero direciona e limita as possibilidades de atuação profissional conforme o sexo - ou exige certas posturas normatizadas conforme o gênero.

Ao buscar discutir e avançar com base nos conceitos clássicos, autores da sociologia contemporânea (ANTHIAS, 2013; 2014; CHAN; GOLDTHORPE, 2007; LAURISON; FRIEDMAN, 2016) revisitaram a obra de Bourdieu (2007) para retomar e ampliar a compreensão sobre classe e status, trazendo status como um aspecto simbólico da estrutura de classes. Para além das relações econômicas, Bourdieu reflete sobre as influências sociais e culturais. Portanto,

uma classe ou uma fração de classe é definida não só por sua posição nas relações de produção, tal como pode ser identificada através de índices - por exemplo, profissão, renda ou, até mesmo, nível de instrução -, mas também pela proporção entre o número de homens e o de mulheres, correspondentes a determinada distribuição no espaço geográfico (que, do ponto de vista social, nunca é neutra), e por um conjunto de características auxiliares que, a título de exigências táticas, podem funcionar como princípios reais de seleção ou exclusão sem nunca serem formalmente enunciados - esse é o caso, por exemplo, da filiação étnica ou do gênero; com efeito, inúmeros critérios oficiais servem de máscara a critérios dissimulados, de modo que o fato de exigir determinado diploma pode ser a maneira de exigir, efetivamente, determinada origem social (BOURDIEU, 2007, p. 97-98).

Outrossim, a noção de habitus ampara o entendimento de habitus de classe, que indica a construção de práticas sociais com sentido coletivo. Habitus pode ser entendido como "[...] um sistema de disposições duráveis e transponíveis que, integrando todas as experiências passadas, funciona a cada momento como uma matriz de percepções, de apreciações e de ações - e torna possível a realização de 
tarefas infinitamente diferenciadas, graças às transferências analógicas de esquemas [...]" (BOURDIEU, 1983, p. 65).

Bourdieu (2007, p. 101) compreende que a classe social é construída e se define "pela estrutura das relações entre todas as propriedades pertinentes que confere seu valor próprio a cada uma delas e aos efeitos que ela exerce sobre as práticas”. Assim, classe não pode ser definida unicamente por propriedade (a exemplo do volume ou estrutura do capital) ou características (sexo, idade, origem social ou étnica), nem por um conjunto de atributos ordenados pela sua posição nas relações de produção. Do mesmo modo, aponta que nem todos os fatores que constituem uma classe dependem uns dos outros igualmente, mas a estrutura que constroem é determinada conforme o maior peso funcional de cada um.

Com relação às teorias de carreira, destaca-se que são orientadas pela neutralidade entre os sexos, ou focam questões referentes às mulheres como grupo homogêneo, forjando uma ideia universal de ser homem e ser mulher. Apesar de a maioria dos estudos tratar o tema de forma neutra (PORTER; WOO; TAK, 2016; SULLIVAN; MAINIERO, 2008), é possível observar como situações, linguagens e espaços cotidianos do trabalho e da vida social são generificadas continuamente. Organizações não são espaços neutros, ao contrário, são marcadas por elementos culturais, socioeconômicos e políticos, que tornam improvável encontrar neutralidade tanto nas escolhas de carreira, como na atuação profissional (FRAGA; ROCHA-DE-OLIVEIRA, 2020). Gênero pode ser considerada como categoria organizadora central na análise da opressão. Entretanto, há uma interconexão de outros aspectos da identidade indissociáveis, como raça e classe. Essa discussão parte da vivência de mulheres negras, que compartilham uma luta individual e coletiva: o racismo contra a pessoa negra e o sexismo contra a mulher (DATTI, 2009).

Ressignificar identidades que foram silenciadas ao longo da história como ocorreu "como as de raça, de classe e de gênero, torna visível quem foi considerada/o coadjuvante até em sua própria história, implícita nas universalizações chanceladas pela normatização hegemônica" (GEMELLI; FRAGA, 2019, p. 2020). McDonald (2016) estuda a interseccionalidade com base na complexidade inter-categorial, o que implica considerar relações amplas de poder, privilégio e desigualdade entre grupos sociais. Assim, a escolha por essa abordagem pode comparar fatores como cargos, educação e renda entre grupos 
como "homens e mulheres, negros e brancos, trabalhadores e classe média, e assim por diante" (McCALL, 2005, p. 1787). Embora a interseccionalidade seja benéfica no sentido de fornecer um instantâneo de questões sistêmicas de desigualdade entre grupos, comumente referenciados e socialmente significativos, ainda há limites para aprofundar na complexidade intragrupo.

A abordagem anticoncorrencial - ou seja, que não sobrepõe os diferentes marcadores de desigualdade sociais - dá complexidade para a interseccionalidade, implicando na desconstrução de amplas categorias analíticas. Possibilita, portanto, expor as diferenças dentro dos grupos e as semelhanças entre os grupos. Uma suposição central da complexidade anticategórica é que as identidades não são estáveis ou objetivamente operacionalizáveis; ao contrário, como postula a teoria queer, as identidades são fluidas, mudam e continuamente são renegociadas nas interações cotidianas. Tal interpretação indica caminhos para a pesquisa social e organizacional queer, embora outras interpretações sejam possíveis.

\section{Método}

Os métodos qualitativos permitem coletar e analisar em profundidade as várias nuances do campo de pesquisa. Seguindo uma perspectiva queer, é possível aprofundar os discursos sobre a diferença, compreendendo atos performativos dessa construção no contexto de trabalho cotidiano (McDONALD, 2016). Ao acompanhar uma trajetória ocupacional por um longo período, é possível compreender os modos de ser individuais e coletivos e como os discursos são valorizados ou desvalorizados em cada espaço profissional.

Para McDonald (2016) a maioria das pesquisas sobre gênero, trabalho e organização considera sexo, gênero, raça, sexualidade e outras facetas da diferença como rótulos arbitrários e os analisa como características estáveis e naturais da vida social. A teoria queer permite uma análise fluida e em transformação, tornando possível uma pesquisa não-normativa, libertando as experiências pesquisadas das categorias pré-definidas.

Para a realização deste trabalho, foi assumida a inter-relação das dimensões biográfica, relacional, organizacional e institucional na escolha e no desenvolvimento das carreiras individuais. Além disso, foi 
dado destaque à dimensão temporal para análise dos estudos de carreira (HUGHES, 1937; MOORE; GUNZ; HALL, 2007). A recolha da história de vida como orientação metodológica torna-se pertinente, por combinar observação, interação e reflexão, constituindo um enfoque biográfico (BERTAUX; KOHLI, 1984). A história de vida contempla uma gama de possibilidades de investigação qualitativa, que inclui técnicas de coleta e interpretação condizentes com seus princípios e seguem a análise narrativa (CHASE, 2005; RIESSMAN, 2003). Narrativas biográficas permitem investigar mudanças objetivas e subjetivas durante uma carreira (DOMECKA; MROZOWIKI, 2005), sem comprometer-se com uma "realidade verificável", mas com os significados dados por quem conta a história (BRUNER, 1991).

Neste estudo, a coleta foi realizada pelo recolhimento das narrativas biográficas e observação. Andrew, o entrevistado, convive com o primeiro autor desde os oito anos de idade e tem sua trajetória acompanhada ao longo deste período. A partir de 2015, depois de seu ingresso em uma companhia de dança, foram recolhidas três narrativas, que duraram em torno de 90 minutos cada uma, e ocorreram em momentos distintos. O primeiro recolhimento da história de vida de Andrew partiu do convite "conte-me sua trajetória", comum aos métodos biográficos. Nos outros dois momentos da coleta biográfica, o questionamento iniciou pelo pedido para contar o que havia acontecido no último ano, incluindo questões direcionadas para trabalho, situação financeira, dificuldades e projetos futuros. Como observação, o trabalho do entrevistado foi acompanhado em espetáculos de dança (Verde Intenso, Salão Grená, Incompatível, Bundaflor-Bundamor e Carmina Burana) e de teatro (Prata Paraíso), em performances em festas da cidade e no seu cotidiano com interações no momento de montagem de vestimentas e no processo de preparação de novos projetos. Além disso, o pesquisador e a pesquisadora seguem o entrevistado em redes sociais e acompanham diferentes momentos de seu trabalho e suas manifestações cotidianas. As impressões destas interações e observações têm sido registradas de modo não contínuo e estruturado em diários de campo. $\mathrm{O}$ entrevistado esteve de acordo com a pesquisa, autorizou e incentivou a utilização do seu nome, bem como leu o relato de sua trajetória.

As entrevistas e impressões registradas nos momentos de interação foram transcritas e organizadas para permitir uma análise narrativa temática e estrutural (RIESSMAN, 2003). O caminho de análise seguido relevou há uma pluralidade de verdades: a cada 
momento que o entrevistado contou sua história, novos entendimentos puderam emergir. Assim, a trajetória de Andrew, elaborada a partir do material coletado, foi contada em uma sequência cronológica, destacando momentos de mudanças de direcionamentos ocorridos. Posteriormente, a trajetória foi analisada com base na teoria apresentada.

\section{A história de Andrew}

Andrew tem 30 anos e desde os 15 voltou sua trajetória para a atividade artística. Entre 2014 e 2018, integrou três companhias de dança em Porto Alegre - a principal companhia de dança da cidade foi sua fonte de renda nesse período. Desde 2018, participa de grupos de dança em São Paulo. Contou que sua trajetória é marcada por vivências laborais bastante distintas, uma vez que a arte, especialmente a dança, é pouco valorizada no Brasil. Raramente profissionais das artes vivem exclusivamente deste trabalho, principalmente fora dos maiores centros culturais do país (Rio de Janeiro e São Paulo). Andrew é gay assumido e adota uma postura queer no modo de vestir cotidiano, o que o torna uma pessoa original no modo de ser.

Nascido em uma cidade pequena, de economia predominantemente agrícola, no sul do Rio Grande do Sul, cresceu praticamente sem contato com o pai e foi criado com sua irmã, sete anos mais velha, pela mãe. Conta que ser o caçula, em uma família predominantemente feminina, influenciou muito sua trajetória, pois sente que não teve algumas das imposições heteronormativas para agir "como menino". Além disso, a falta de recursos da família o levou a utilizar muitas das roupas antigas da irmã durante a infância e adolescência. Acredita que isto contribuiu para formar seu gosto na forma de vestir, que não tem preocupação com "o gênero da roupa", sendo predominantemente uma "forma de vestir criativa", como ele mesmo define.

Hoje gosto de sair com sucata no meio das minhas roupas, de customizar roupas e de usar muita coisa que trabalha com a desconstrução de gênero, que passa pelo masculino, pelo feminino, sem problema nenhum. Isso é tão natural para mim, desde sempre, que às vezes fico pensando... como isso se deu ao longo da minha vida? $\mathrm{Eu}$ acho que eu nunca decidi... do nada, vou ser desse jeito. Foi um processo e vai estar sempre em processo, porque cada vez a gente descobre, eu pelo menos (risos), descubro alguma coisa que surge no 
meu corpo, na minha vida, de um jeito diferente. Sou artista, tenho minha sexualidade bem resolvida, nunca tive um pai morando comigo; nunca tive uma figura paterna. [...] Então nunca tive ninguém dizendo: 'Não! Tu não pode fazer isso. Isso é feio, isso é errado, isso é um horror'. Nunca tive ninguém me recriminando. Acho que isso ajudou a não criar nenhuma barreira.

Quando lembra da infância, destaca que "desde sempre eu soube que era artista, soube que queria trabalhar profissionalmente com arte. Não sabia quanto tempo eu levaria para chegar neste ponto". A mãe, apesar dos reduzidos recursos financeiros e de viver em uma cidade com limitadas possibilidades culturais, desde cedo incentivou o filho e a filha a apreciarem todas as manifestações artísticas que tinham acesso. Assim, seus primeiros passos na dança, foram aos 15 anos, ainda na pequena cidade em que vivia, a convite de um professor de uma escola de dança. Não houve qualquer censura por parte da família para que ele fizesse balé clássico, atividade predominantemente direcionada para meninas na região. "Minha família, meus colegas, meus amigos sempre me apoiaram em tudo o que eu fiz."

Aos 17 anos, Andrew buscou uma formação tradicional e iniciou um curso superior em dança, em uma universidade de Porto Alegre, capital do estado, localizada a 120 quilômetros de sua cidade. Percebendo as poucas possibilidades artísticas do local onde vivia, aos 20 anos mudou para a capital e foi trabalhar no comércio, pois não tinha experiência com dança e precisava de recursos para se manter na cidade. "A necessidade me obrigou a ficar sete anos no comércio para poder me manter profissionalmente". Foi nesse período que sua forma de vestir começou a mudar significativamente, passando a colocar cada vez mais peças consideradas femininas em seu guarda-roupa. Também mudou seu direcionamento do balé clássico para atividades de dança contemporânea e começou a se envolver em projetos de diferentes companhias de dança. No entanto, todos os trabalhos eram temporários, sem garantia contínua de ganhos financeiros. "A maioria dos profissionais de dança no Brasil ganha dinheiro dando aula e eu não me sentia preparado e queria trabalhar com dança”. Nas escolas, aprendeu as técnicas e tipos de dança; nas companhias, os processos de criação e de organização dos espetáculos; na faculdade, a teoria com maior foco no corpo, na anatomia, e nos movimentos.

Eu comecei a faculdade de dança, mas eu não concluí. Não concluí porque era licenciatura e eu não tinha vontade de dar aula, nem de 
fazer um concurso para dar aula em uma escola; que eu precisaria de um diploma. Às vezes ficam perguntando. 'Na área da dança precisa ter faculdade?'. Depende para que. Tem gente que quer levar uma vida como professor e eu não quero, quero atuar como bailarino tudo que eu puder. E algum dia se eu me achar apto ou se a necessidade me obrigar, talvez eu dê aula. E a faculdade é um meio que te facilita isso, mas não é obrigatório.

Esse tempo de trabalho no comércio tomou muita energia e limitou sua atuação na dança, contudo, permitiu a inserção na cena artística porto-alegrense. O primeiro trabalho como bailarino foi em 2012. Em 2014, aos 26 anos, ingressou na companhia de dança de Porto Alegre, única companhia da cidade com pagamento regular. Existem outras companhias reconhecidas na região, porém sem salário fixo, pagam apenas cachê pela participação em cada espetáculo, recursos inconstantes que normalmente exigem dos bailarinos uma segunda atividade profissional para sobreviver.

Esse foi um período de dedicação exclusivo a dança: todas as manhãs na companhia, exercício, inglês e atuação em outros projetos à tarde. Nos finais de semana, fazia apresentações ou assistia espetáculos para aprender. A formação consistia no aprendizado de técnicas e movimentos por meio de horas de repetição de exercícios físicos e observação da atuação de outros artistas da cidade.

Em 2016, contou sobre uma mudança na direção de sua trajetória: buscou formações em teatro, depois de decidir-se pela dança contemporânea, que exige maior atuação do bailarino em cena. Também foi quando começou a receber propostas para atuar como performer em festas, algo que relata como natural. Naquele momento, Andrew passou a se identificar não mais como bailarino, mas como artista:

Hoje (entrevista de 2016) posso me dedicar ao teatro para agregar ao meu trabalho como bailarino, como artista. Quero experimentar outras fisicalidades. Quero ter outras experiências com meu corpo, que não sejam apenas o que já tenho com a dança. Então faço uma oficina de teatro e performance que me possibilita ver outras coisas interessantes relativas às atividades do corpo. Hoje eu posso dedicar meu tempo integralmente à arte e me manter trabalhando com dança.

Se eu for pensar como artista, acho que tem a questão de performance, de eu ser uma pessoa mais excêntrica e que consequentemente tem um estilo um pouco mais over. Outras coisas que são interessantes de me ver como artista e trabalhando com isso é que se eu não trabalhasse também, é uma coisa que é da vida... tem a 
questão de ser performer na noite, por exemplo, receber pessoas em festa... ou de... estar apenas sendo eu mesmo, que as pessoas acham que é excêntrico, mas é o meu normal. Acho que é devido ao fato de ser artista. De poder usar de todo o meu corpo e o meu entorno com tudo o que é diferente dos outros, mas me favorece. Então... ser performer é estar inserido num meio queer na noite de Porto Alegre.

Em 2017, estreiou sua primeira peça, intitulada Prata Paraíso, inspirada na peça Ptedordáctilos de Nicky Silver. A peça com três atores e cinco personagens que alternavam entre si foi uma obra de posicionamento gay na cidade. Segundo Andrew, é uma temática que o atrai, por representar um ativismo queer, conectado com a forma como vê o mundo: "A forma como eu levo minha vida me fortalece nessa forma de ser e agir".

As contínuas apresentações de espetáculos na capital, no estado e em outras cidades pelo país contribuíram para seu reconhecimento como artista. "Hoje (entrevista de 2017) já tenho incentivo, reconhecimento, pessoas que acreditam no meu trabalho. Isso é um estímulo para continuar. Sempre tem alguém perto dizendo: "segue em frente!". Pela atuação em sua primeira na peça, Andrew ganhou em 2018 o troféu Açorianos de melhor ator, principal premiação do Rio Grande do Sul na área de teatro.

Como consequência, aumentaram os convites para performances em festas, quando as pessoas procuravam alguém divertido, para animar convidados e convidadas. No entanto, Andrew vê essa atividade mais como uma forma de diversão do que de trabalho e não espera que seja sua fonte principal de renda. Considera que não tem conhecimento profissional para atuar como "animador de festas".

A figura estranha que pareço para pessoas é o meu normal. Esse meu normal está presente em qualquer horário do dia que eu quiser. Se eu quiser sair vestido deste jeito que as pessoas acham interessante; de manhã, de tarde, de noite, eu saio. Às vezes ganho para isso, às vezes não.

O processo de criação e de transformação foi bastante destacado por Andrew nas entrevistas, relatando como vivencia a carreira em diferentes contornos. "Eu preciso ser outro e ser eu, ao mesmo tempo. Preciso ser diferente em cada companhia, ser diferente na noite, em cada trabalho... essa versatilidade. E ao mesmo tempo não deixar de ser eu mesmo." 
Em 2018, após encerrar o contrato na companhia de dança de Porto Alegre, Andrew mudou-se para São Paulo na expectativa de assumir novos desafios. Iniciou atividades em algumas companhias e pretende ficar na cidade por algum tempo, para trabalhar em espaços que contribuirão na sua formação e continuidade na carreira artística. No horizonte próximo, Andrew pretende ter uma experiência internacional, para aprimorar a técnica e aprender novas fisicalidades.

\section{Queering análises}

Ao analisarmos a carreira de Andrew é possível notar uma trajetória não linear, marcada pelas dimensões de classe, gênero e sexualidade nos diferentes momentos de sua vida. Nesse percurso pouco tradicional (para alguns pontos de vista) emergem reflexões queer sobre carreira - tanto na relação com o trabalho, como na forma pela qual os marcadores sociais interferem, contribuem e se somam para a construção de suas vivências. Primeiramente destaca-se que sua conduta em diferentes esferas da vida segue uma atitude queer (PULLEN et al., 2016; SOUZA, 2017). Andrew evidencia uma ruptura com construções estabelecidas de gênero, classe, trabalho, ainda que em um primeiro momento estivesse ligado à construção da identidade dos bailarinos. Tal identidade passa por mudanças na medida que outras manifestações artísticas começam a fazer parte de seu repertório.

Numa dimensão material cotidiana, vestimentas e acessórios de Andrew, normalmente customizados, rompem com a binariedade de gênero por meio da combinação de peças consideradas masculinas e femininas, além de incluir artefatos pouco convencionais como adornos: origamis, cartões de crédito, latas de refrigerante, brinquedos e outras formas de sucata. Além disso, as diversas tatuagens, marcas de sua trajetória, também se conectam com a forma livre como se apresenta. Em termos de classe, há uma ruptura com a expectativa de mobilidade social ascendente e circulação por diversos espaços sociais sem a preocupação de incorporar elementos estratificados de gosto (BOURDIEU, 2007) e de modo de vida de um determinado grupo.

Assim, como recurso didático para analisar sua trajetória, destacam-se cinco pontos principais:

Primeiro, a predefinição binária trabalho-lazer é desconstruída, já que para Andrew os dois espaços se confundem. Muitas vezes é 
chamado para "trabalhar" em festas dançando e fazendo performances e para ele isto é uma forma de diversão, tendo em vista que demanda apenas ser ele mesmo e manter seu estilo. No balé, a busca pela dança contemporânea e companhias que dão mais liberdade para a criação e valorização das diferenças dos participantes, rompe com a visão tradicional de dança como técnica por meio da repetição exaustiva e busca pela perfeição, como apresentado por Wainwright e Turner (2006). Mais recentemente, a opção por companhias e espetáculos politicamente posicionados, bem como a intensificação de sua atuação em redes sociais, mostram sua trajetória dinâmica que cada vez mais articula lazer-trabalho-ativismo.

Segundo, acompanhar a carreira de Andrew ao longo do tempo, com suas mudanças e recomeços mostra um zig zag (BOYLSTEIN; MAGGARD, 2013), no qual em alguns momentos recebe rótulos de desvio (BECKER, 1993; 2008), por não seguir a perspectiva ascendente de remuneração e status, comumente associados ao desenvolvimento de uma carreira. São exemplos os momentos em que deixa atividades mais tradicionais e com remuneração fixa para se dedicar à dança ou quando prefere ingressar em projetos que valorizem o ativismo social de discussão de gênero e sexualidade - ao invés daqueles de maior destaque na cena artística ou de maior rentabilidade. Tais elementos desviantes são pontos que reforçam a construção de uma carreira queer, que não se alinha aos conceitos habituais de sucesso, ou seja, maiores ganhos financeiros ou cargos de maior destaque. Nesse sentido, sua trajetória está ligada às atitudes em defesa das diferenças, das liberdades de escolha e trajetória, das suas próprias construções de gênero e de sexualidade, que para uma parte significativa da sociedade brasileira (ainda) representam desvio.

Terceiro, o contexto de origem marca sua trajetória, seja pela valorização da arte, seja pela desconstrução de gênero, com base nos papeis sociais vividos na família e pela falta de recursos financeiros. Em especial, os gastos contidos da família fizeram com que se tornasse natural a utilização das roupas tidas como "femininas", da mãe e da irmã. Ao mesmo tempo, Andrew aprendeu a valorizar peças de sucata como define - os itens para diferenciar sua vestimenta. Atualmente, tais elementos estão muito presentes no modo de viver sua carreira como um todo, profissional e pessoalmente, assim como nos projetos que vislumbra para construção de planos futuros. Ao contrário de um impedimento determinado pela condição social, as vivências de Andrew 
apresentam construções de percursos próprios, que ocorreram ao deparar-se com diferentes campos de possibilidades. São projetos individuais e coletivos (VELHO, 2003) que trilharam a construção de carreira como trajetória de reconhecimento e valorização de diferenças individuais.

Quarto, a classe social de origem mostra elementos tanto de estímulo como de maior dificuldade para a construção de sua trajetória, pontos que foram apreendidos tomando a diferença de maneira positiva. A construção de sentidos é ligada diretamente ao processo de socialização - relacionado com os habitus de classe, forma pela qual os sentidos são construídos e compartilhados (ABRANTES, 2013; LAURISON; FRIEDMAN, 2016). Os sentidos de carreira muitas vezes estão atrelados aos habitus de classe, criando segmentação e restrição de oportunidades no mercado de trabalho. Andrew não pertence as classes médias tradicionais do país e teve uma organização familiar predominantemente feminina, algo que permitiu maior liberdade na construção de sua identidade e para suas escolhas profissionais. Em geral, jovens da classe média são pressionados a assumir profissões semelhantes as de seus pais e mães ou carreiras convencionais, uma forma de reprodução do status familiar intergeracionalmente. Cabe ressaltar, entretanto, que o acesso limitado a recursos para investir e avançar em sua carreira - e mesmo para permanecer e viver exclusivamente da atividade artística - tem sido um limitador, ainda que não represente impeditivo para prosseguir em sua trajetória.

Quinto, a trajetória narrada permite perceber como os conceitos de gênero, sexualidade e classe se integram na construção da carreira e permitem compreensões distintas de atividades consideradas como desviantes, particularidades da atividade artística como já destacava Becker (1951). A pessoa está inserida em um tempo-espaço social e sua posição e relação com o contexto interfere em suas decisões e ações (ABBOTT, 1997), o que pode limitar ou potencializar sua vivência profissional a partir dos conflitos, na forma como vivencia os papeis sociais (HUGHES, 1937) e mantém sua individualidade.

Assim, considera-se que buscar uma aproximação da teoria queer com a discussão de carreira - que envolva a valorização das diferenças - permite avançar na discussão, ao proporcionar abertura e potencial de amplitude para o conceito. A compreensão do contexto sócio-histórico, baseada nas perspectivas individuais, possibilita tomar as diferenças de gênero, de classe, de raça, de sexualidade e de outras 
diversidades. Geralmente, as diferenças são excluídas ou negligenciadas nos principais enfoques de carreira, nos quais predominam identidades organizacionais hegemônicas.

\section{Considerações finais}

A pesquisa com pessoas que atuam em atividades não tradicionais (BECKER, 2008; CRESSEY, 1932) amplia a discussão sobre as fronteiras sociais existentes na construção das carreiras. Gênero, sexualidade e classe são marcadores sociais que constroem fronteiras no mercado de trabalho, mas também espaços de aprendizado e resistência que podem contribuir nas trajetórias profissionais. Seguir a perspectiva queer permite que o foco esteja na desconstrução de conhecimentos e identidades estabelecidas e no reconhecimento e na valorização de diferenças. No presente estudo, o destaque foi dado para trajetórias profissionais que rompem com as convenções que constroem espaços de inclusão desviante e limitam acessos.

Nesta pesquisa, a trajetória de Andrew - bailarino, gay, de classe baixa, nascido no sul do Brasil - foi apresentada para ilustrar uma carreira queer. Suas falas mostram ações que valorizam a diferença como ação política, tanto na esfera profissional como no cotidiano. Assim, há três contribuições principais que surgem deste artigo: 1) a ênfase para a interseccionalidade no campo de carreiras, apontando as múltiplas diferenças que somam e marcam trajetórias; 2) a apresentação das potencialidades da teoria queer para aprofundar e dar novas direções e dimensões para os estudos de carreira; 3) o uso de metodologias qualitativas para os estudos de carreira.

Primeiramente, abordar a interseccionalidade (ANTHIAS, 2013; 2014; McDONALD, 2016; MORRIS, 2017) de gênero, classe, raça e sexualidade permite compreender que as múltiplas dimensões da diferença ocorrem simultaneamente e que os estudos que dão enfoque apenas para uma correm o risco de negligenciar os efeitos da potencialização de características integradas. Neste estudo, a interseccionalidade permitiu analisar de modo integrado gênero, classe e sexualidade na formação de uma trajetória individual, identificando como estes conceitos se articulam e contribuem para a construção de novas dimensões de produção da diferença e, como consequência, formas de resistir a elas. A carreira de Andrew mostra as múltiplas rupturas que foram desbravadas, uma vez que os campos profissionais 
são espaços com gênero e com classe e que as artes tradicionais, como o balé, normalmente estão destinadas às classes com maior poder econômico. Além disso, a normatização do balé clássico como forma de arte, em que há uma clara definição de papeis de gênero, é contraposta com formas contemporâneas de dança com maior valorização da criação e de uma individualidade que pode romper com o binarismo de gênero.

Em segundo lugar, a teoria queer (MCDONALD, 2016), surge como abordagem interdisciplinar que permite uma análise crítica das trajetórias profissionais, valorizando particularidades e diferenças. Ainda que alguns trabalhos (FRAGA; ROCHA-DE-OLIVEIRA, 2020; ITUMA; SIMPSON, 2009; LE; JOGULU; RENTSCHLER, 2014) destaquem que gênero, raça, etnia (e outros marcadores sociais) levam a construções de trajetórias distintas, a maior parte dos estudos de carreira assume acriticamente esses conceitos, usualmente adotando uma noção binária (FRAGA; GEMELLI; ROCHA-DE-OLIVEIRA, 2019), que direciona a enquadramentos determinantes Assim, deixam de reconhecer e valorizar a diferença ao reforçar normatizações sociais. Em contrapartida, a abordagem queer surge como base teórica robusta para analisar, em especial, carreiras não tradicionais, permitindo que diferentes dimensões que caracterizam e contribuem para sua construção sejam destacadas.

Por fim, a escolha de um método qualitativo longitudinal entrevistas narrativas e observação - se mostra pertinente para queering carreiras, uma vez que permite a aproximação com a pessoa entrevistada, para que se sinta à vontade para falar sobre sua trajetória e contar como foram vivenciadas suas andanças nesse percurso. Outrossim, acompanhar Andrew via redes sociais - com seu consentimento (WILLIS, 2017) - permitiu ingressar em seu cotidiano, seguindo em detalhes suas experiências e contando com representações gráficas e outras formas de expressão que corroboram e contrapõem os momentos de entrevista, contribuindo para o aprofundamento da compreensão da carreira.

\section{Referências}

ABBOTT, Andrew. Of time and space: The contemporary relevance of the Chicago School. Social forces, v. 75, n. 4, p. 1149-1182, 1997. 
ABRANTES, Pedro. Socialization and inequality: A biographical approach to the working class in Portugal. Current Sociology, v. 61, n. 7, p. 984-1002, 2013.

ANTHIAS, Floya. Hierarchies of social location, class and intersectionality: Towards a translocational frame. International Sociology, v. 28, n. 1, p. 121-138, 2013.

ANTHIAS, Floya. The intersections of class, gender, sexuality and 'race': The political economy of gendered violence. International Journal of Politics, Culture, and Society, v. 27, n. 2, p. 153-171, 2014.

BARUCH, Yehuda; SZÚCS, Nóra; GUNZ, Hugh. Career studies in search of theory: The rise and rise of concepts. Career Development International, v. 20, n. 1, p. 3-20, 2015.

BARUCH, Yehuda; VARDI, Yoav. A fresh look at the dark side of contemporary careers: toward a realistic discourse. British Journal of Management, 1-18. v. 27, n. 2, p. 355-372,2016.

BECKER, Howard. Outsiders: Estudos de sociologia do desvio. Rio de Janeiro, RJ: Zahar, 2008.

BECKER, Howard S. The professional dance musician and his audience. American Journal of Sociology, v. 57, n. 2, p. 136-144, 1951.

BECKER, Howard S. A história de vida e o mosaico científico. In: BECKER, Howard S. Métodos de pesquisa em ciências sociais. São Paulo: Hucitec, 1993.

BERTAUX, Daniel; KOHLI, Martin. The life story approach: A continental view. Annual review of sociology, v. 10, n. 1, p. 215-237, 1984 .

BOURDIEU, Pierre. Questões de sociologia. Rio de Janeiro: Marco Zero, 1983.

BOURDIEU, Pierre. A Distinção: Crítica social do julgamento. São paulo: Edusp; Porto Alegre: Zouk, 2007.

BOYLSTEIN, Craig; MAGGARD, Scott R. Small-Scale Marijuana Growing: Deviant Careers as Serious Leisure. Humboldt Journal of Social Relations, v. 35, n. 1, 2013. 
BRUNER, Jerome. The narrative construction of reality. Critical inquiry, v. 18, n. 1, p. 1-21, 1991.

BRISCOE, Jon P.; HALL, Douglas T.; DEMUTH, Rachel L. Frautschy. Protean and boundaryless careers: An empirical exploration. Journal of vocational behavior, v. 69, n. 1, p. 30-47, 2006.

CHAN, Tak Wing; GOLDTHORPE, John H. Class and status: The conceptual distinction and its empirical relevance. American sociological review, v. 72, n. 4, p. 512-532, 2007.

CHARLES, M. W.; ARNDT, L. M. R. Gay- and Lesbian-Identified Law Enforcement Officers: Intersection of Career and Sexual Identity. The Counseling Psychologist, v. 41, n. 8, 1153-1185, 2013

CHASE, Susan. Narrative inquiry: multiple lenses, approaches, voices. In: DENZIN, N; LINCOLN, Y. The Sage handbook of qualitative research. $3^{\text {a }}$ ed. Thousand Oaks: Sage Publications, 2005.

CRESSEY, Paul Gealby. The Taxi Dance-hall: A Sociological Study in Commercial Recreation \& City Life. Chicago: University of Chicago Press, 1932.

DATTI, Paul A. Applying social learning theory of career decision making to gay, lesbian, bisexual, transgender, and questioning young adults. The Career Development Quarterly, v. 58, n. 1, p. 54-64, 2009.

DELUCA, Gabriela; ROCHA-DE-OLIVEIRA, Sidinei; CHIESA, Carolina Dalla. Projeto e metamorfose: contribuições de Gilberto Velho para os estudos sobre carreiras. Revista de Administração Contemporânea, v. 20, n. 4, p. 458-476, 2016.

DELUCA, Gabriela; ROCHA-DE-OLIVEIRA, Sidinei. Inked careers: Tattooing professional paths. BAR-Brazilian Administration Review, v. 13, n. 4, 2016.

DOMECKA, Markieta; MROZOWICKI, Adam. Professional biographies in transition: comparing experiences of workers and business people in post-socialist Poland. In: Proceedings of World Congress of the International Institute of Sociology, Stockholm, Sweden, 2005. 
FAULKNER, Robert. Career concerns and mobility motivations of orchestra musicians. In: HARPER, Douglas; LAWASON, Helene. The Cultural Study of Work, 139-158, 2003.

GEMELLI, Catia Eli; FRAGA, Aline Mendonça. Resenha: RIBEIRO, Djamila. O que é lugar de fala? Belo Horizonte: Letramento, Justificando, 2017. Cadernos de Gênero e Diversidade, Vol o5, N. 03 Jul. - Set., 2019

FRAGA, Aline Mendonça; PRESTES, Vanessa Amaral; ROCHA-DEOLIVEIRA, Sidinei; MEDEIROS, Igor Baptista de Oliveira; FEIJÓ; Carla dos Santos. "Para além do arco-íris": trajetórias de carreira de casais homossexuais. Revista Psicologia Organizações e Trabalho, v. 19, n. 3, p. 662-670, 2019.

FRAGA, Aline Mendonça; GEMELLI, Catia Eli; ROCHA-DE-OLIVEIRA, Sidinei. Cenário das publicações científicas em carreira e gênero. Revista Pensamento Contemporâneo em Administração, v. 13, n. 3, p. 158-178, 2019.

FRAGA, Aline Mendonça; ROCHA-DE-OLIVEIRA, Sidinei. Mobilidades no labirinto: tensionando as fronteiras nas carreiras de mulheres. Cad. EBAPE.BR, Rio de Janeiro, v. 18, n. spe, p. 757-769, Nov. 2020.

FRIEDMAN, Sam; O’BRIEN, Dave; LAURISON, Daniel. 'Like skydiving without a parachute': How class origin shapes occupational trajectories in British acting. Sociology, v. 51, n. 5, p. 992-1010, 2017.

GAZTAMBIDE-FERNÁNDEZ，Rubén; VANDERDUSSEN，Elena; CAIRNS, Kate. "The Mall" and "the Plant" Choice and the Classed Construction of Possible Futures in Two Specialized Arts Programs. Education and Urban Society, v. 46, n. 1, p. 109-134, 2014.

GUEST, David; STURGES, Jane. Living to work-working to live: conceptualizations of careers among contemporary workers. Handbook of career studies, p. 310-326, 2007.

GUNZ, Hugh; MAYRHOFER, Wolfgang. Rethinking career studies. Facilitating conversation across boundaries with the Social Chronology Framework. Cambridge: Cambridge Press, 2019. 
HUGHES, Everett C. Institutional office and the person. American journal of sociology, v. 43, n. 3, p. 404-413, 1937.

HUGHES, E.C. Men and their work. Chicago: The University of Chicago Press, 1958.

ITUMA, Afam; SIMPSON, Ruth. Theboundaryless' career and career boundaries: Applying an institutionalist perspective to ICT workers in the context of Nigeria. Human Relations, v. 62, n. 5, p. 727-761, 2009.

JONES, Sandra J. Complex subjectivities: Class, ethnicity, and race in women's narratives of upward mobility. Journal of Social Issues, v. 59, n. 4, p. 803-820, 2003.

KAPLAN, David M. Career anchors and paths: The case of Gay, Lesbian, \& Bisexual workers. Human Resource Management Review, v. 24, n. 2, p. 119-130, 2014.

KHAPOVA, Svetlana N.; ARTHUR, Michael B. Interdisciplinary approaches to contemporary career studies. Human Relations, v. 64, n. 1, p. 3-17, 2011.

KING, Andrew. Queer categories: queer (y) ing the identification 'older lesbian, gay and/or bisexual (LGB) adults' and its implications for organizational research, policy and practice. Gender, Work \& Organization, v. 23, n. 1, p. 7-18, 2016.

LAURISON, Daniel; FRIEDMAN, Sam. The class pay gap in higher professional and managerial occupations. American Sociological Review, v. 81, n. 4, p. 668-695, 2016.

LAWRENCE, Barbara S. Careers, social context and interdisciplinary thinking. Human Relations, v. 64, n. 1, p. 59-84, 2011.

LE, Huong; JOGULU, Uma; RENTSCHLER, Ruth. Understanding Australian ethnic minority artists' careers. Australian Journal of Career Development, v. 23, n. 2, p. 57-68, 2014.

MAINIERO, Lisa A.; GIBSON, Donald E. The Kaleidoscope Career Model revisited: How midcareer men and women diverge on authenticity, balance, and challenge. Journal of Career Development, v. 45, n. 4, p. 361-377, 2018. 
MAYRHOFER, Wolfgang; MEYER, Michael; STEYRER, Johannes. Contextual issues in the study of careers. In: GUNZ; Hugh; PEIPERL, Maury. (Eds.). Handbook of career studies, p. 215-240, 2007.

McCALL, Leslie. The Complexity of Intersectionality. Signs, v. 30, n.3p. 1771-1800, 2005.

McDONALD, James. Occupational segregation research: Queering the conversation. Gender, Work \& Organization, v. 23, n. 1, p. 19-35, 2016.

MISKOLCI, Richard. A Teoria Queer e a Sociologia: o desafio de uma analítica da normalização. Sociologias, v. 11, n. 21, p. 150-182, 2009.

MOORE, Celia; GUNZ, Hugh; HALL, Douglas T. Tracing the historical roots of career theory in management and organization studies. In: GUNZ; Hugh; PEIPERL, Maury. (Eds.). Handbook of career studies, p. 13-38, 2007.

MORRIS, Max. "Gay capital" in gay student friendship networks: An intersectional analysis of class, masculinity, and decreased homophobia. Journal of Social and Personal Relationships, v. 35, n. 9, p. 1183-1204, 2018.

NG, Eddy SW; SCHWEITZER, Linda; LYONS, Sean T. Anticipated discrimination and a career choice in nonprofit: A study of early career lesbian, gay, bisexual, transgendered (LGBT) job seekers. Review of Public Personnel Administration, v. 32, n. 4, p. 332-352, 2012.

PARNELL, Martha Keeton; LEASE, Suzanne H.; GREEN, Michael L. Perceived career barriers for gay, lesbian, and bisexual individuals. Journal of Career Development, v. 39, n. 3, p. 248-268, 2012.

PRASAD, Pushkala; D' ABATE, Caroline; PRASAD, Anshuman. Organizational Challenges at the Periphery: Career Issues for the Socially Marginalized. In: GUNZ, Hugh P.; PEIPERL, Maury. Handbook of career studies. Thousand Oaks: SAGE publications, 2007. p. 169-188

PORTER, Caitlin; WOO, Sang Eun; TAK, Jinkook. Developing and validating short form protean and boundaryless career attitudes scales. Journal of Career Assessment, v. 24, n. 1, p. 162-181, 2016. 
PULLEN, Alison et al. Postscript: Queer endings/queer beginnings. Gender, Work \& Organization, v. 23, n. 1, p. 84-87, 2016.

RIESSMAN, Catherine Kohler. Analysis of personal narratives. In: HOLSTEIN; James, GUBRIUM. Jaber F. Inside interviewing: New lenses, new concerns, p. 331-346, 2003.

RONAI, Carol. R.; FAUK, Rebecca. Dancing with Identity: Narrative Resistance Strategies of Male and Female Stripteasers. In: HARPER, Douglas; LAWASON, Helene. The Cultural Study of Work, 116-29, 2003.

SOUZA, Eloisio Moulin de. A teoria queer e os estudos organizacionais: revisando conceitos sobre identidade. Revista de Administração Contemporânea, v. 21, n. 3, p. 308-326, 2017.

STEFFY, Kody. Willful versus woeful underemployment: Perceived volition and social class background among overqualified college graduates. Work and Occupations, v. 44, n. 4, p. 467-511, 2017.

SULLIVAN, Sherry E.; BARUCH, Yehuda. Advances in career theory and research: A critical review and agenda for future exploration. Journal of management, v. 35, n. 6, p. 1542-1571, 2009.

SULLIVAN, Sherry E.; MAINIERO, Lisa. Using the kaleidoscope career model to understand the changing patterns of women's careers: Designing HRD programs that attract and retain women. Advances in Developing Human Resources, v. 10, n. 1, p. 32-49, 2008.

THOMPSON, Mindi N.; SUBICH, Linda M. Development and exploration of the experiences with classism scale. Journal of Career Assessment, v. 21, n. 1, p. 139-158, 2013.

VELHO, Gilberto. Projeto e metamorfose: antropologia das sociedades complexas. 3.ed. Rio de Janeiro: Jorge Zahar, 2003

WAINWRIGHT, Steven P.; TURNER, Bryan S. 'Just crumbling to bits'? An exploration of the body, ageing, injury and career in classical ballet dancers. Sociology, v. 40, n. 2, p. 237-255, 2006.

WILLIS, Roxana. Observations online: Finding the ethical boundaries of Facebook research. Research Ethics, v. 15, n. 1, p. 1-17, 2019. 


\section{Queering Careers: Gender, Class, and Sexuality Intersectionalities in the Career of a Male Ballet Dancer}

ABSTRACT: Gender, sexuality, and class influence professional trajectories and converge for the understanding of career contexts. This paper aims to analyze a queer career based on the experience of a gay artist that was born in southern Brazil from a lower-class background. For that purpose, career concepts are (re)discussed using the queer theory approach. The discussion of gender, sexuality, and class is deepened through the intersected analysis of these elements during his professional path. The methodological path consists of a biographical focus, seeking to combine observation, interaction and reflection during and after obtaining the life story to be told. Andrew, the interviewee, is a ballet dancer, an actor, and performs at private parties. He adopts a queer posture in his daily life, dressing and acting in his way wherever he is. The main contributions of this article are: 1) the emphasis on intersectionality for career studies, pointing out the multiple differences that add to and influence career paths; 2) the potential of queer theory to deepen and give new directions and dimensions to career studies; 3) the use of qualitative methodologies for career studies.

KEYWORDS: Career. Queer. Gender. Sexuality. Social Class.

Sidinei ROCHA-DE-OLIVEIRA

Bacharel e Mestre em Administração pela Universidade Federal do Rio Grande do Sul (UFRGS). Doutor em Administração pela Université Pierre MendèsFrance - Grenoble 2 em cotutela com a UFRGS. Professor Associado no curso de Administração da UFRGS. Coordenador do Programa de Pós-Graduação em Administração (2019 a 2021). Tem interesse de pesquisa nas áreas de inserção profissional e mobilidade social, carreiras em ocupações não tradicionais e as interseccionalidades de marcadores sociais de diferenças (classe, gênero, raça e sexualidade etc.) na construção dos mercados de trabalho e carreiras.

Aline Mendonça FRAGA

Doutora, Mestra e Bacharela em Administração pela Universidade Federal do Rio Grande do Sul (UFRGS). Professora de Administração (FASEG), pesquisadora do Observatório Internacional de Carreiras (OIC - PPGA/EA/ UFRGS) e membra do Núcleo de Estudos e Pesquisas em Gênero e Sexualidade (NEPGS/IFRS-Osório). Tem interesse de pesquisa no campo de mobilidades, migrações e carreiras e suas interseccionalidades com marcadores sociais de diferenças/diversidades, como gênero, sexualidade e classe.

Recebido em: 23/10/2019 Aprovado em: 25/o1/2021 